\title{
A Comparison of the Severity of Malocclusion Between Two Centres in the United Kingdom and Malaysia : A Preliminary Investigation
}

Sarah HAG, Sundralingam S.A Comparison of the Severity of Malocclusion between Two Centres in th United Kingdom and Malaysia: a Preliminary Investigation. Annals Dent. Univ. Malaya 1995;2:15-19.

\begin{abstract}
The preliminary investigation was carried out to assess the severity of malocclusion between two centres, the dental schools in Leeds, United Kingdom and Kuala Lumpur, Malaysia. A total of 99 study models were analysed using the Index of Orthodontic Treatment Need (IOTN). The study models were of patients aged 8 to 15 years, equally distributed between male and female patients taken from the undergraduate and staff clinics. Forty nine and fifty study models were analysed at the Leeds Dental School and Faculty of Dentistry, University of Malaya, respectively. From this observation, it appeared that the sample of patients treated at the Faculty of Dentistry, Kuala Lumpur presented approximately $25 \%$ higher with cases in the severe end of the malocclusion based on the dental health component and almost $70 \%$ more with the aesthetic component. Factors contributing to this finding are discussed.
\end{abstract}

\author{
*Sarah H.A. Ghani, B.D.S., M.Sc (Orthodon- \\ tics) M.D.O.R.C.P.S. (Glasgow) (Author) \\ **S. Sundralingam (Co-Author) \\ * Orthodontic Lecturer \\ Dept. of Children's Dentistry and Orthodontics \\ Faculty of Dentistry \\ 59100 Kuala Lumpur \\ Malaysia. \\ ** Dental Student \\ Leeds Dental Institute \\ Clarendon Way, Leeds \\ United Kingdom.
}

Key Words: IOTN, dental health and aesthetic component.

\section{INTRODUCTION}

One of the major problems in orthodontic diagnosis and assessment of orthodontic treatment need, is that an orthodontic anomaly is not a disease with series of well recognised symptoms. It is a variation from the norm in which treatment is based upon the evaluation of certain dental characteristics in otherwise healthy patients.

The World Health Organization (WHO) in 1977 has proposed requirements for an ideal index; and of these the most important are:

\section{Validity characteristic that enables an index to measure what it purports to measure. reproducibility which enables the same findings to be achieved by the same or different observers and at different times. ease of use - the simpler the better and acceptibility - to the profession and public alike.}

There appears to be a need for some method of defining treatment needs and standards. Because of a shortfall in resources and concern about the needs and standards of orthodontic treatment in general, a rational system of prioritizing malocclusion is desirable, various indices have been widely practised in Sweden, Norway and recently in the United Kingdom. 2,3,4,5,6.

The idea of an index is not new, certainly indices have been used to categorise medical and dental disorders for the purposes of epidemiology, research and to allocate patients into categories of treatment need. In other area of dentistry, indices have been used for some years such as DMFT index and periodontal indices.

In orthodontics, however, malocclusion is unique in that it presents a number of unrelated traits to which patient react in different ways. Several indices have been developed before to assess malocclusion but failed to gain widespread use except for two indices: Grainger's Treatment Priority Index and Summer Occlusal Index ${ }^{7}$. Again, these indices were found to be cumbersome and time-consuming.

In 1989, Brook and Shaw ${ }^{5}$ from two university departments (Manchester and Bristol) and four orthodontic societies have collaborated to develop two indices of malocclusions.

1. The Index of Orthodontic Treatment Need (IOTN) consists of two independent components: the Dental Health Component (DHC) based on the Swedish index, and the Aesthetic Component (AC).

2. The Peer Assessment Rating Index (PAR Index) or otherwise known as Index of Treatment Standard.

These indices have been validated by a panel of dentists, comprising of consultant orthodontists, specialist practitioners, community dental officers, general practitioners and others from the Dental Practice Board to ensure that they reflected contemporary orthodontic opinion. With these simpler indices, the use would certainly gain momentum all over the world. The aim of this preliminary investigation is to exercise th.e use of the Index of Orthodontic Treatment Need (JOTN) by comparing the severity of malocclusion from iwo different centres, the Leeds Dental School and Faculty of Dentistry, Kuala Lumpur. 


\section{MATERIALS AND METHODS}

A preliminary study was performed using the Index of Orthodontic Treatment Need (IOTN) on 99 study models by an elective dental student from Leeds. The principal investigator was initially calibrated in the use of the index which allowed reliable comparisons be made between two different centres.

Due to the fact that orthodontic treatment has to be justified on either aesthetic or dental health grounds and occasionally on both aspects, two components of assessments are required.

The Dental Health component: This component has 5 categories ranging from grade 1 (no need for treatment) to grade 5 (great need for treatment) which may be applied clinically or to study models. (Table 1) This is further simplified into a transparent plastic rulers for easy use (Figure 1). The most severe occlusal trait of the five grades is identified for any particular patient indicating the need for treatment. The following characteristics are assessed for the dental health components; missing teeth, overjet, crossbites, contact point displacement and overbite.

The Aesthetic Component: This consists of a scale of 10 photographs showing different levels of dental attractiveness (Figure 2). The dental attractiveness of patients or study models can be identified and ranked according to this scale.

Grades 1-4 represent: No/slight need for treatment 5-7 represent: Borderline need and

8-10 represent: Definite need for treatment on aesthetic grounds.

\section{SCORING PROCEDURE}

The study sample consisted of 99 study models; 49 and 50 sets were analysed at the Leeds Dental School followed by the Faculty of Dentistry, Kuala Lumpur, respectively. The study models were randomly selected of patients aged between 8-15 years, equally distributed between males and females; taken from the undergraduate and staff clinics (Table 2). The principal operator was calibrated using 10 sets of study models varying in grades for both components on two different occasions. Being the only observer for both centres, it was important to establish a reasonably good level of calibration to be able to substantiate a meaningful comparison. Intraexaminer reliabity was tested using a weighted Kappa statistic ${ }^{8}$. Having successfully completed the calibration course, the sample scoring procedure began. The dental health and aesthetic components of each study model were scored using the IOTN transparent ruler and the series of photographs, respectively.

\section{Results}

\section{Error analysis}

The calibration of 10 sets of study models was performed. For the assessment of dental health need for treatment, the examiner exhibited an almost perfect level of agreement, Kappa statistics 0.90 whilst the aesthetic need
Table 1 Dental Health Component Gradings

\section{Grade 5 (Great Need treatment)}

5.i Impeded eruption of teeth (except for third molars) due to crowding displacement the presence of supernumerary teeth, retained deciduous teeth and any pathological cause.

5.h Extensive hypodontia with restorative implications (more than 1 tooth missing in any quadrant) requiring prerestorative orthodontics.

5.a Increased overjet greater than $9 \mathrm{~mm}$.

5.m Reverse overjet greater than $3.5 \mathrm{~mm}$ with reported masticaitory and speech difficulties.

5.p Defects of cleft lip and palate and other craniofacial anoma lies.

5.s Submerged deciduous teeth.

\section{Grade 4 (Need treatment)}

4.h Less extensive hypodontia requiring pre-restorative orthodontics or orthodontic space closure to obviate the need for a prosthesis.

4.a Increased overjet greater than $6 \mathrm{~mm}$ but less than or equal to $9 \mathrm{~mm}$.

4.b Reverse overjet greater than $3.5 \mathrm{~mm}$ with no masticatory or speech difficulties.

$4 . \mathrm{m}$ Reverse overjet greater than $1 \mathrm{~mm}$, but less than $3.5 \mathrm{~mm}$ with recorded masticatory and speech difficulties.

4.c Anterior or posterior crossbites with greater than $4 \mathrm{~mm}$ discrepancy between retruded contact position and intercuspal position.

4.1 Posterior lingual crossbite with no functional occlusal contact in one or both buccal segments.

4.d Severe contact point displacements greater than $4 \mathrm{~mm}$.

4.e Extreme lateral or anterior open bites greater than $4 \mathrm{~mm}$.

4.f Increased and complete overbite with gingival or palatal trauma.

4.t Partially erupted teeth tipped and impacted against adjacent teeth.

4.x Presence of supernumerary teeth.

\section{Grade 3 (Borderline need)}

3.a Increased overjet greater than $3.5 \mathrm{~mm}$ but less than or equal to $6 \mathrm{~mm}$ with incompetent lips.

3.b Reverse overjet greater than $1 \mathrm{~mm}$ but less than or equal to $3.5 \mathrm{~mm}$.

3.c Anterior or posterior crossbites with greater than $1 \mathrm{~mm}$ but less than or equal to $2 \mathrm{~mm}$ discrepancy between retruded contact position and intercuspal position.

3.d Contact point displacements greater than $2 \mathrm{~mm}$ but less than or equal to $4 \mathrm{~mm}$.

3.e Lateral or anterior open bite greater than $2 \mathrm{~mm}$ but less than or equal to $4 \mathrm{~mm}$. (Deep overbite complete on gingival or palatal tissues but no trauma.)

3.f Deep overbite complete on gingival or palatal tissues, but no trauma.

\section{Grade 2 (Little)}

2.a Increased overjet greater than $3.5 \mathrm{~mm}$, but less 1 han or equal to $6 \mathrm{~mm}$ with competent lips.

2.b Reverse overjet greater than $0 \mathrm{~mm}$, but less than or equal to $1 \mathrm{~mm}$.

2.c Anterior or posterior crossbite with less than or equal to 1 $\mathrm{mm}$ discrepancy between retruded contact position and intercuspal position.

2.d Contact point displacements greater than $1 \mathrm{~mm}$, but less than or equal to $2 \mathrm{~mm}$.

2.e Anterior or posterior openbite greater than $1 \mathrm{~mm}$, but less than or equal to $2 \mathrm{~mm}$.

2.f Increased overbite greater than or equal $3.5 \mathrm{~mm}$ without ginglval contact.

2.g Prenormal or postnormal occlusions with no other anomalies (includes up to half a unit discrepancy).

\section{Grade 1 (None)}

1. Extremely minor malocclusions including contact point displacements less than $1 \mathrm{~mm}$. 


\begin{tabular}{|c|c|c|c|c|c|}
\hline $\mid$ & {$\left[\begin{array}{ll}3 \\
4 \\
2\end{array}\right]$} & $\begin{array}{r} \\
5\end{array}$ & 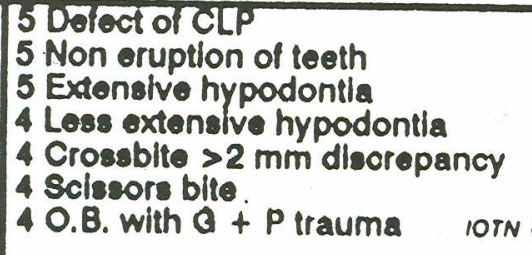 & $\begin{array}{l}\text { 30.8. With NO G+ P tiauma } \\
3 \text { crossble } 1.2 \mathrm{~mm} \text { discrepancy } \\
20.8 \text {. D } \\
2 \text { Dov. From full interdig } \\
2 \text { Crossbite \& } 1 \mathrm{~mm} \text { discrepancy } \\
\text { O VICTORIA UNIVERSITY OF MANCMESTER }\end{array}$ & $\begin{array}{l}\text { DISPLACEMENT } \\
\text { OPEN BITE } \\
\begin{array}{llll}Y & 1 & 1 \\
4 & 3 & 2 & 1\end{array}\end{array}$ \\
\hline
\end{tabular}

Figure 1. Photo of dental health component RULER.

\begin{tabular}{|l|c|c|c|}
\hline \multicolumn{3}{|c|}{ Table: 2} & \multicolumn{3}{|c|}{ Distribution of study models, $\mathrm{n}=99$} \\
\hline \multirow{3}{*}{ Undergraduate } & $\begin{array}{c}\text { Leeds } \\
20 \\
\mathrm{~m}=10 ; \mathrm{f}=10\end{array}$ & $\begin{array}{c}\text { Kuala Lumpur } \\
25 \\
\mathrm{~m}=12 ; \mathrm{f}=13\end{array}$ & $\begin{array}{c}\text { Total } \\
45\end{array}$ \\
\hline Staff clinics & $\begin{array}{c}29 \\
\mathrm{~m}=15 ; f=14\end{array}$ & $\begin{array}{c}25 \\
\mathrm{~m}=13 ; f=12\end{array}$ & 54 \\
\hline & 49 & 50 & 99 \\
\hline
\end{tabular}

a substantial level of agreement. Kappa statistics 0.80 . The examiner was therefore, found to be successfully calibrated.

Scores for Dental Health Component (Table 3)

Results obtained in Leeds Dental School revealed that out of 49 study models assessed for orthodontic treatment need on dental health grounds (DHC):

no score for Grade 1 category i.e no need for treatment

11 (22 percent) scored Grade 2 i.e little need for treatment.

22 (45 percent) scored Grade 3 i.e bordeline need for treatment.

16 (33 percent) scored Grade 4 i.e need for treatment, and none in Grade 5 category i.e great need for treatment.

Whilst in the Faculty of Dentistry, Kuala Lumpur, 50 stuidy models were assessed for the Dental Health Component (DHC):

Table 3 : Severity of Malocclusion Dental Health Component

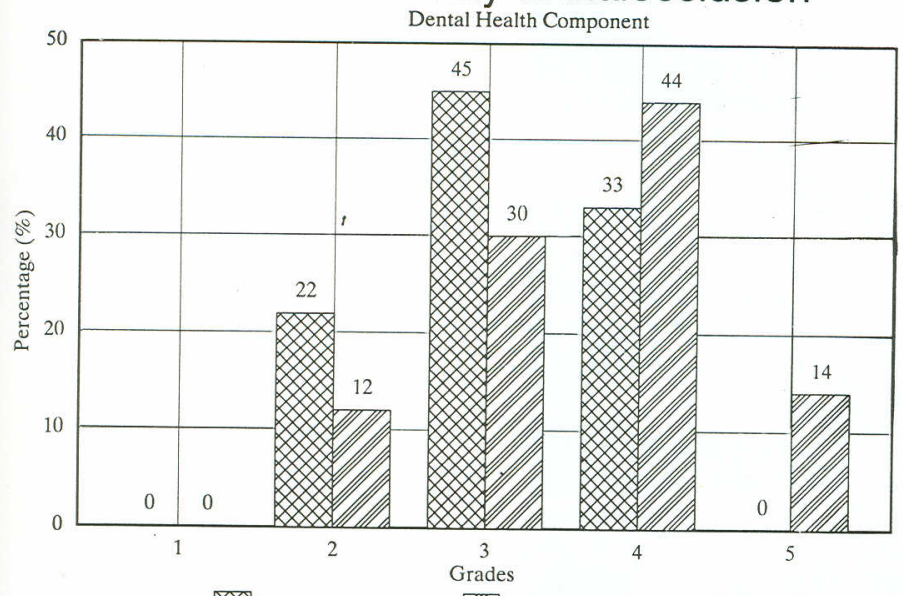

Leeds Dental School Dental Faculty, K.L no score for Grade 1 category i.e no need for treatment.

6 (12 percent) scored Grade 2 i.e little need fo treatment.

15 ( 30 percent) scored Grade 3 i.e bordeline need for treatment.

22 (44 percent) scored Grade 4 i.e need for treatment and

7 (14 percent) score Grade 5 i.e great need fo treatment.

\section{Scores for Aesthetic Component (Table 4)}

The scores for aesthetic component was performed concurrently with the dental health component and the results from Leeds Dental showed that:

10 (20 percent) was seen in Grade $1-4$ score; which represent no or slight need for treatment.

33 (67 percent) Grade 5-7 scores i.e borderline need for treatment and only 6 (12 percent) Grade 8-10 scores for definite need for treatment on aesthetic grounds.

Comparatively, in the Dental Faculty, Kuala Lumpur 3 (6 percent) in Grade 1-4 scores,

13 ( 26 percent) in Grade $5-7$ scores and 34 (68 percent) in Grade 8-10 scores for definite need of treatment on aesthetic grounds.

\section{DISCUSSION}

The use of IOTN as a tool of objectively assessing treatment need is gaining popularity within the field of

Table 4: Severity of Malocclusion

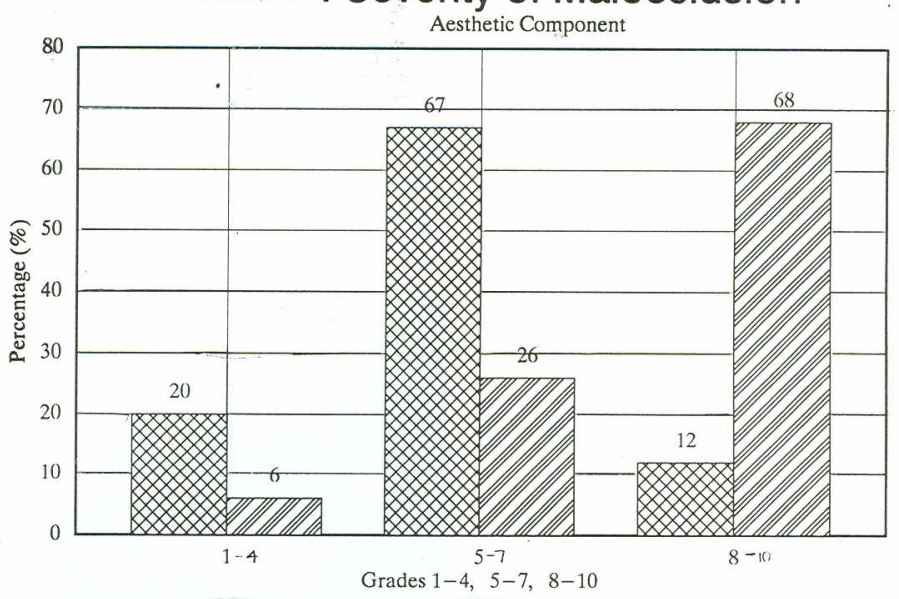

Leeds Dental School Dental Faculty, K.L 
orthodontics in Europe and the United Kingdom. Since an increasing number of individuals are now calibrated in the use of IOTN, reliable comparisons can now be made between different centres.

In Malaysia and the region of South East Asia, this investigation certainly represents the first report on the use of an index in orthodontics. The severity of malocclusion and the orthodontic treatment need were compared, it was interesting to note from the results that the majority of the cases treated in the Faculty of Dentistry, Kuala Lumpur fell into the severe end of malocclusion range for both the dental health and aesthetic components.

Closer observation on the dental health component revealed that the Dental School in Leeds treated greater percentage of cases in Grades ? (22\%) and $3(45 \%)$ with little and borderline need for treatment. Further decline in Grades 4 (33\%) and none in Grade 5.

This is further confirmed with the aesthetic component gradings where again, greater percentage of cases treated were in Grades 1-4 (20\%) with slight need for treatment; $67 \%$ in grades $5-7$ with borderline need and a marked decline in grades $8-10(12 \%)$ for definite need for treatment. Whilst, in Kuala Lumpur the majority of cases were found to be in Grade 3 (30\%), highest percentage in Grade 4 (44\%) and $14 \%$ in Grade 5 with regards to the dental health component. Looking at the aesthetic component up to $68 \%$ of the presenting cases fell into the most severe groups i.e Grades 8-10 with definite need for treatment.

This finding has projected clearly that the centre in Leeds is treating less severe orthodontic cases as compared to the centre in Kuala Lumpur. Several factors could attribute to this finding. It could simply mean that patients who presented here in Kuala Lumpur primarily had mort abroad. Social background, ethnic variation in growth, development of facial skeleton and occlusion, demographic and standard of living differ significantly between the two samples. These factors however, are beyond our control.

Other obvious reasons should also be considered. The availability of manpower where dentist - population ratio is better proportioned in the United Kingdom compared to Malaysia. Thus, it is possible to render better monitoring of the dental health status and developing malocclusion, allow good referrals, early detection and carry out interceptive orthodontic treatment to help eliminate or reduce the severity of developing malocclusions. The National Health Services (NHS) in the United Kingdom practise a system of payment to the general dental practitioners upon completion of simple and supervised orthodontic treatment at an acceptable standard; which in itself could help monitor the types of malocclusion treated, the treatment outcome and the cost. This system particularly protects the patient from unlawful orthodontic practice.

The shortage of orthodontists in Malaysia too, contributes to limited orthodontic services and long waiting lists giving rise to late and severe presentation of malocclusion.

The dental awareness towards malocclusion from the two centres also vary quite considerably. The interest and knowledge of the patient, parents and peer group towards orthodontic treatment in the U.K are higher so much so that patients are assessed at an early stage of life for potential orthodontic problems. This has allowed the clinician to maximise preventive and interceptive orthodontic procedures to eliminate or reduce future problems. The high score in Grades 5 and 8-10 seen in the sample from Kuala Lumpur, to a minor extent, is due to the inclusion of the cleft patients treated by the staff together with other normal orthodontic patients.
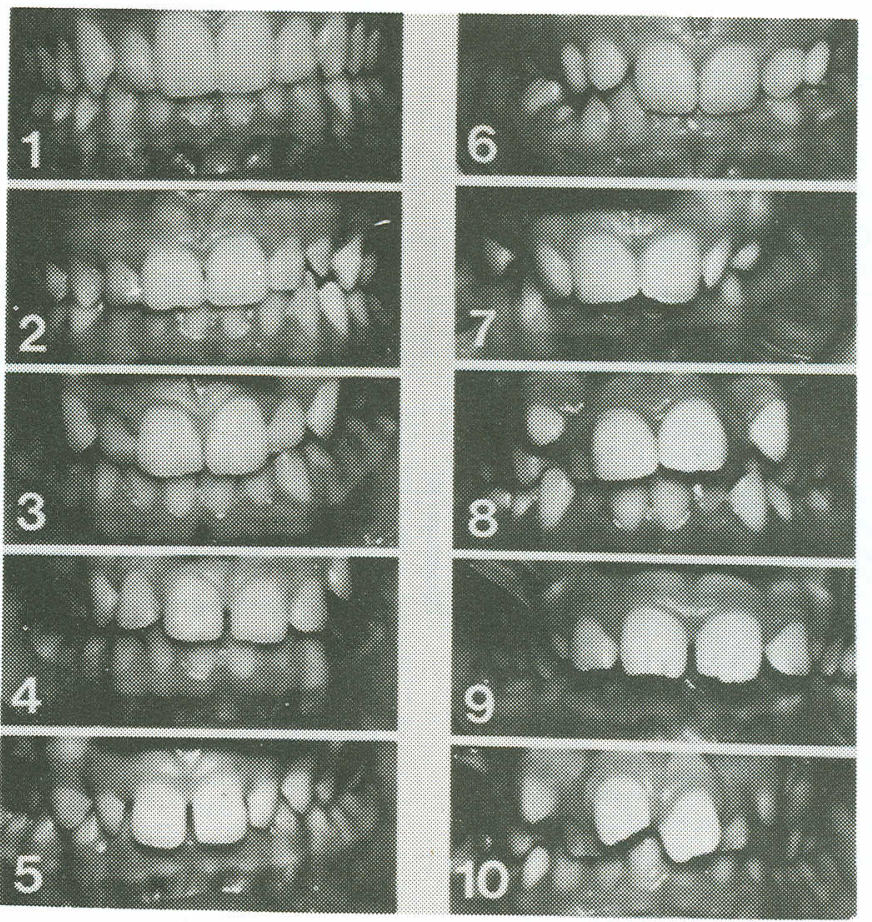
This is not the case with cleft patients in the U.K where special care units and centres are set-up separate from the normal orthodontic clinics.

\section{CONCLUSION}

The severity of malocclusion between two centres Leeds and Kuala Lumpur revealed that the majority of cases treated at the Faculty of Dentistry Kuala Lumpur fell into the severe end of the malocclusion range for both the dental health and aesthetic components. The Index of Orthodontic Treatment Need (IOTN) proved to be a useful and easy tool for comparison. Further utilization of this index is highly recommended.

\section{ACKNOWLEDGEMENT}

The authors are grateful to Associate Professor Dr. Raja Latifah for the statistical guidance.

\section{REFERENCES}

1. Houston WJB, Stephens CD and Tulley WJ. A textbook of orthodontics, Wright 1992, 2nd ed; 4-50.

2. Mohlin B. Need and demand for orthodontic treatment in a group of women in Sweden. European Journal of Orthodontics 1982: 4, 231-242.

3. My berg $\mathrm{N}$ and Thilander B. An evaluation of the duration and the results of orthodontic treatment. Scandinavian Journal of Dental Research 1973a; 18: 85-91.

4. Myberg N and Thilander B. Orthodontic need of treatment of Swedish schoolchildren from objective and subjective aspects. Scandinavian Journal of Dental Research 1973b; 81: 81-84.

5. Brook PH and Shaw WC. The development of an index for orthodontic treatment priority. European Journal Of Orthodontics 1989; 11: 309-332.

6. Richmond S. A critical evaluation of orthodontic treatment in the General Dental Services of England and Wales, Ph.D thesis, University of Manchester, 1990.

7. Richmond S, Roberts CT and Andrews M. Use of the Index of Orthodontic Treatment Need (IOTN) in Assessing the Need for orthodontic Treatment Pre and Post-appliance Therapy. British Journal of Orthodontics 1994; 21: 175-184.

8. Buchanan IB, Downing A and Stirrups DR. A Comparison of the Index of Orthodontic Treatment Need Applied Clinically and to Diagnostic Records. British Journal of Orthodontics 1994; 21: 185-188. 